\title{
Implementation and Benefits of PhilHealth E-Claims in Government Hospitals
}

\author{
Ethelmay R, Romero \\ ethelmayromero@gmail.com \\ Laguna State Polytechnic University, Sta. Cruz, Laguna, 4009, Philippines
}

\begin{abstract}
The study entitled, Implementation and Benefits of PhilHealth E-Claims of Government Hospitals is a descriptive research design with the use of purposive non-probability sampling technique as basis for the distribution of questionnaire in type of Likert Scale and close-ended interview guide sheet to twenty seven (27) authorized personnel of Government Hospitals to determine the 1) demographic profile of the respondents; 2) level of eClaims quality service in terms of Claim Eligibility Web Service (CEWS), Electronic Claims Submission (ECS) and Claim Status Verification (CSV); 3) the implementation and benefits of E-Claims of Government Hospital in Laguna; 4) level of perception of authorized personnel in the eClaims system, and 5) the significant effect of PhilHealth Circular No. 30, s-2017 to the level of implementation and benefits of Government Hospitals in Laguna.
\end{abstract}

Based on the overall analysis on the level of eClaims quality service in terms of CEWS, it is "Moderately Implemented"; ECS is "Moderately Implemented"; and CSV is "Fully Implemented". Therefore, the researcher inferred that the PhilHealth Circular No. 30, s-2017 has significant effect on the level of implementation of Government Hospitals in Laguna.

For all the given result of the data, the researcher highly recommends to update and to enhance the two phases of eClaims system which are the CEWS and the ECS which could complete the essential features and the implementation of the said system. The PhilHealth must actively monitor the compliance of all of their Accredited Health Care Institution (HCI) which could reduce the length of their compliance. And they must also continue to develop and sustain a program for the improvement of the employee's performance in order to enhance clients' satisfaction.

Keywords: eClaims; ECS; CEWS; HCI; PhilHealth;

\section{Introduction}

The technological advancement of information and communication, has brought along innovative ways and method to streamline workflows and make lives easier. In the workplace, automated system has a lot of benefits which add value to customer's satisfaction and convenience that enables the company or the organization to gain more competitive advantage over the other competitors. (Khan, 2016). A major advantage that an automated system has in contrast to a traditional business, is that, it can be easily assessed and it has a 
wide reach. But, Nanehkaran (2013) stressed that transforming from traditional business method to electronic commerce method is difficult and there were many factors to be consider for the companies to adapt them with electronic commerce factors.

The services of many public and government institutions now, used an automated kind of transaction in order for them to attain and improve efficiency and effective services at the same time.

The Philippine Health Insurance Corporation (PhilHealth) is one of the government institutions who adapt the modern way of claims system transactions. The efficiency issues which are manifested in turnaround-time indicator, is PhilHealth's challenge as claim forms have to be physically submitted to PhilHealth and entered by the Local Health Insurance Offices (LHIOs) or the PhilHealth Regional Offices (PROs). Using paper claims is a time-taking process and providers can face a tough time trying to process large numbers of patient's claims.

That's why, they created a framework that would migrate the current manual PhilHealth claims benefit processing to an automated one. Where, all the accredited Health Care Institution (HCI), are required to shift to electronic claims (eClaims) to achieve greater efficiency in claims processing and improve claims data integrity.

Fortunately, the outcome of this new digital strategy of the PhilHealth, will benefit not just all the accredited Health Care Institution (HCI) but, the partner provider and all the PhilHealth members too.

As defined on the PhilHealth eClaims Implementation Guide (2013) PhilHealth Claims Eligibility Web Service (CEWS) or the Phase 1 of e-Claims Project allows the hospital to check whether or not the patientsare registered with PhilHealth and has required contributions to avail of benefits. This project is expected to speed up the eligibility verification process at the hospital level and may reduce incidence of return-to-hospital claims due to member eligibility concerns.

PhilHealth Circular No. 21 s. 2014 explained that claim eligibility web service allows the Health Care Institutions (HCI) to determine eligibility of patient to avail of PhilHealth benefit by encoding all required fields in the Health Information Technology Provider (HITP).

Garfield S. (2017) stated that maintaining the records of an organization from the time they are created up to their eventual disposal includes classifying, storing, securing, archiving, and destroying records. The ideal information lifecycle management process provides an easy method for content to be reviewed, with the reusable content preserved and the other content archived on suitable software.

Managing the information system is not only include software systems, but the entire set of business processes and resources that are used to pull together information from functional or tactical systems. Data is presented in a user-friendly and timely manner so that entire system is designed where the company or the organization will meet its strategic and tactical goals. (Management Hub, 2014).

As cited by Stadler et. al., (2016) in the context of software architecture, the term "web service" refers to software functionality or a set of software functionalities with the purpose of higher efficiency by different clients to different purposes.

It is also an instrument which enables to perform various tasks, where the interface and functions provided are consistent with rules and regulation by the service description. (Chang \& Mao-Sheng, 2016). 
As mentioned by Fenza (2013) web services have attained a leading role, promising interoperability between different applications of heterogenrous environments. Web services aims at supporting the interpretation of data information, in order to automate the discovering of suitable services in open environment applications.

The below mentioned literatures are related to the study since Electronic Claim Submission (ECS) is also one of the important features of the eClaims.

American Medical Association (AMA) \& Connecticut State Medical Association (2013) defined "electronic claim" as a paperless patient claim form generated by computer software that is transmitted electronically over computer connection to a health insurer or the third $\left(3^{\text {rd }}\right)$ party payer for processing and payment. Electronic claims submission helps to reduce the administrative burden and expense generally associated with manual claims processing and submission.

Electronic transaction is rapidly transforming the way in which enterprises are interacting among each other as well as with consumers or clients and Governments. As a result of changes in the landscape of ICTs, e-commerce is now approving rapidly in several emerging markets even in public services in a developingcountries. (UNCTAD, 2015).

As revealed by Doherty et. al., (2013) clinical care increasingly requires healthcare organizations to access patient information that may be distributed across sites held in variety of paper and electronic formats and represented as mixtures of narrative, structured, coded and multi-media entries. Shifting toward electronic system transaction from a paper-based record system with a view to imptrove efficiency and effectiveness of patient care and better satisfaction rate.

Emblem Health (2018) mentioned that eliminating paper claims transaction and submitting electronic claims system creates advantages like quicker claims submission, which means faster reimbursement, less paper claims to stock and complete, simplified record keeping by eliminating lost claims paperwork and reduced clerical time and the costs to process mail paper claims.

As stated on the PhilHealth Circular No. 16 s. 2016 electronic claim submission (ECS) is designed in such a way as to permit transmission to PhilHealth in the form of an Extensible Markup Language (XML).

The below literatures are related to the present study since Claim Status Verification (CSV) is one of the features of the eClaims that helps in enhancing the customers' satisfaction.

Bridgestone (2017) explained that automated claim status verification is a "lights out" process which queries the status of every claim on file and notifies which claims are ready for the next step of the process. This type of claim verification also enhanced the productivity report and improved denials management process where it can notify denied claims at the earliest possible time.

American Medical Association (AMA) \& Connecticut State Medical Association (2013) revealed the medical practice was encouraged to switch to an automated system to request claim transmission. These claims were assisted in tracking the acceptance or the rejection of all the claims sent. When the claims notified as rejected, it can quickly and easily correct and resubmit the claim electronically.

PhilHealth Circular No. 21 s. 2014 explained that electronic claims status verification allows the Health Care Institution (HCI) to track and verify the status of its claims by providing the Claim Series 
Number $(\mathrm{CSN})$.

PhilHealth Circular No. 16 s. 2016 mentioned that claim status verification facilitate claims status inquiry on the side of the hospital and provide an online means of claims reconciliation between hospital and the Philhealth.

\section{Methods}

Using a descriptive research design, the data for this study were tabulated and analyze using Mean, Standard deviation and the Pearson $r$ to determine the level of the clerks' profile; and the quality service of the eClaims in terms of Claim Eligibility Web Service (CEWS), Electronic Claim Submission (ECS), and claim Status Verification (CSV). And to determine the effect between the variables.

The researcher used statistical measure such as mean, standard deviation, and Pearson $\mathrm{r}$. The mean is intended to convey indicate or refer to significant, also was computed in order to express the variation perception of the respondents.

The standard deviation is a quantity calculated to indicate the extent of deviation for a group as a whole. Formula was utilized to know the variability or dispersion of the respondents.

Pearson $r$ is a statistical measure of the length of a linear relationship between paired data. Furthermore, positive values denote positive linear correlation; negative values denote negative linear correlation. A value of 0 denote no linear correlation.

\section{Results}

Graph 1. Demographic Profile of the Respondents in terms of Age

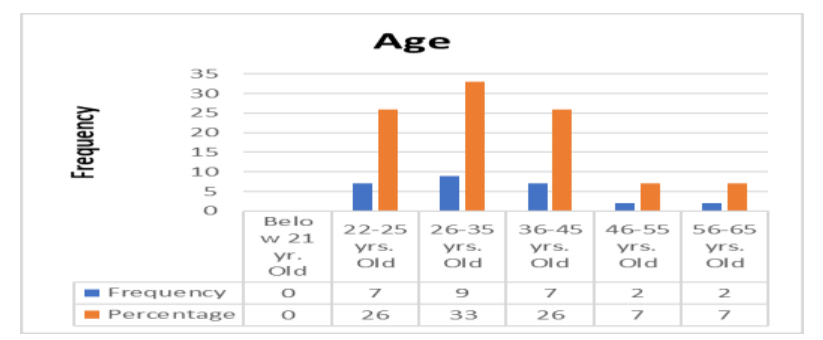

Demographic Profile of the respondents in terms of Age that the highest percentage is thirty three percent $(33 \%)$ or 9 authorized personnel which are "26-35 years old". Followed by the percentage of twenty six percent $(26 \%)$ or 7 authorized personnel are "22-25 years old" and "36-45 years old". While the lowest percentage of seven percent (7\%) or 2 authorized personnel are " $46-55$ years old" and " $56-65$ years old". The data shows that the majority of the authorized personnel are 26-35 years old.

Graph 2. Demographic Profile of the Respondents in terms of Gender

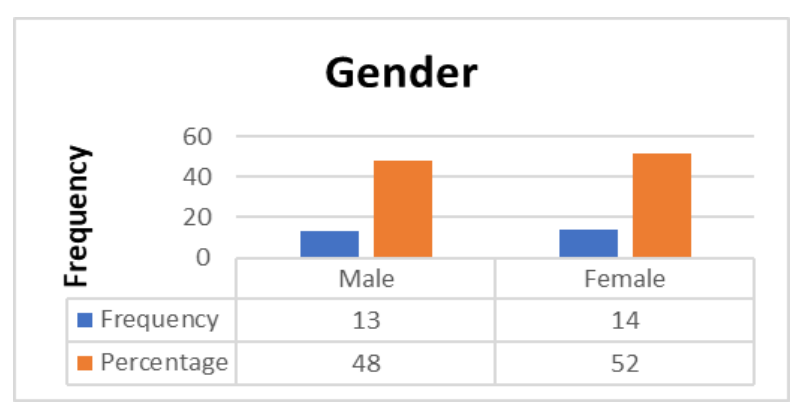


Demographic Profile of the respondents in terms of Gender where thirteen (13) or $48 \%$ are males and fourteen (14) or $52 \%$ are females.

Graph 3. Demographic Profile of the Respondents in terms of Years in Service

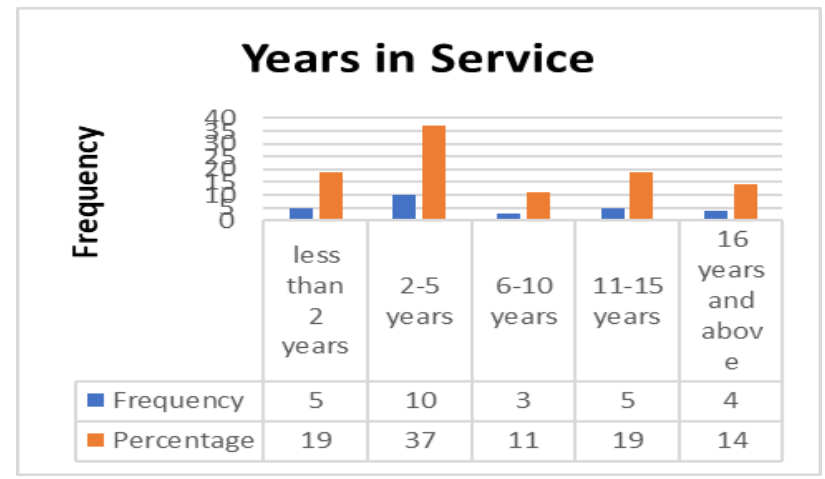

Demographic Profile of the respondents in terms of Years in Service where there are fifteen (15) or $56 \%$ of the respondents who have less than 6 years in service; there are three or $11 \%$ with 6 - 10 years in service; there are five or $19 \%$ respondents with 11 - 15 years in service; and four or $15 \%$ of the respondents with at least sixteen (16) years in service. The data shows that majority of the authorized personnel are 2-5 years in service.

Graph 4. Demographic Profile of the Respondents in terms of Designation

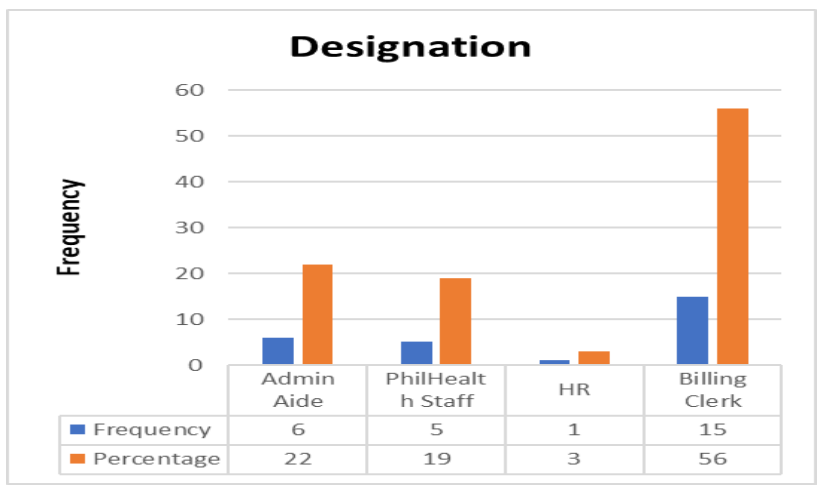

Demographic Profile of the respondents in terms of Designation that the highest percentage is $56 \%$ or fifteen (15) authorized personnel are "Billing Clerk". Followed by $22 \%$ or six (6) authorized personnel are "Admin Aide". Followed by 19\% or five (5) authorized personnel are "Philhealth Staff'. While the lowest percentage of $3 \%$ or one (1) authorized personnel are "HR". The data shows that majority of the authorized personnel are Billing Clerk. 
Table 1. Level of Claims Eligibility Web Service (CEWS)

\begin{tabular}{|l|l|l|l|}
\hline Questions & Mean & SD & Remarks \\
\hline $\begin{array}{l}\text { It securely identifies the eligibility of the } \\
\text { patient/member to avail PhilHealth benefits. }\end{array}$ & 4.59 & 0.57 & Fully Implemented \\
\hline $\begin{array}{l}\text { It speeds up the eligibility verification process of the } \\
\text { member/patient in availing Philhealth benefits. }\end{array}$ & 3.89 & 0.70 & Moderately Implemented \\
\hline $\begin{array}{l}\text { It can quickly determine whether the } \\
\text { patient/member met all the required criteria as a } \\
\text { PhilHealth beneficiary. }\end{array}$ & 3.85 & 0.72 & Moderately Implemented \\
\hline $\begin{array}{l}\text { It set a high standard for all the electronic } \\
\text { transactions. }\end{array}$ & 3.96 & 0.65 & Moderately Implemented \\
\hline $\begin{array}{l}\text { It clearly serves to instruct Philhealth } \\
\text { member/patient with compliance to particular } \\
\text { deficiencies. }\end{array}$ & 4.30 & 0.72 & Fully Implemented \\
\hline Weighted Mean & $\mathbf{4 . 1 2}$ & $\mathbf{0 . 5 5}$ & Moderately Implemented \\
\hline
\end{tabular}

Legend:

$\begin{array}{lll}\text { Scale } & \text { Range Remarks } \\ 5 & 4.20-5.00 & \text { Fully Implemented } \\ 4 & 3.40-4.19 & \text { Moderately Implemented } \\ 3 & 2.60-3.39 & \text { Rarely Implemented } \\ 2 & 1.80-2.59 & \text { Poorly Implemented } \\ 1 & 1.00-1.79 & \text { Not Implemented }\end{array}$

The level of eClaims quality service in terms of Claims Eligibility Web Service (CEWS). It shows that the employees "Fully Implemented" the Claims Eligibility Web Service (CEWS) in terms of: It securely identifies the eligibility of the patient/member to avail PhilHealth benefits. (mean $=4.59, \mathrm{SD}=0.57)$; and It clearly serves to instruct Philhealth member/patient with compliance to particular deficiencies (mean $=4.30$, $\mathrm{SD}=0.72$ ). They "Moderately Implemented" eClaims quality service in terms of Claims Eligibility Web Service (CEWS) in terms of: It speeds up the eligibility verification process of the member/patient in availing Philhealth benefits. (mean $=3.89, \mathrm{SD}=0.70$ ); It can quickly determine whether the patient $/ \mathrm{member}$ met all the required criteria as a PhilHealth beneficiary (mean $=3.85 ; \mathrm{SD}=0.72$ ); and It set a high standard for all the electronic transactions (mean $=3.96 ; \mathrm{SD}=0.65$ ).

Generally, the employees "Moderately Implemented" eClaims quality service in terms of Claims Eligibility Web Service $(\mathrm{CEWS})($ mean $=4.12, \mathrm{SD}=0.55)$.

Nagamouttou et. al., (2015) stated that web services are disseminated and self-sufficient computational elements that solve specific tasks, varying from undemanding requests to multifaceted business. It also helps to strengthen the enrollment process by standardizing decisions so that personnel do not influence the selection process. 
Table 2. Level of Electronic Claims Submission (ECS)

\begin{tabular}{|l|l|l|l|}
\hline Questions & Mean & SD & Remarks \\
\hline It can submit claim online immediately. & 4.04 & 0.71 & Moderately Implemented \\
\hline $\begin{array}{l}\text { It is a very high electronic solution in enhancing } \\
\text { client satisfaction. }\end{array}$ & 3.74 & 0.66 & Moderately Implemented \\
\hline It improves consistency and data quality. & 3.81 & 0.62 & Moderately Implemented \\
\hline $\begin{array}{l}\text { It improves the internal workflows in relation to } \\
\text { PhilHealth transactions. }\end{array}$ & 3.85 & 0.66 & Moderately Implemented \\
\hline It simplifies the record keeping. & 4.07 & 0.92 & Moderately Implemented \\
\hline Weighted Mean & $\mathbf{3 . 9 0}$ & $\mathbf{0 . 6 0}$ & $\begin{array}{l}\text { Moderately } \\
\text { Implemented }\end{array}$ \\
\hline
\end{tabular}

Legend:

$\begin{array}{lll}\text { Scale } & \text { Range } \text { Remarks } \\ 5 & 4.20-5.00 & \text { Fully Implemented } \\ 4 & 3.40-4.19 & \text { Moderately Implemented } \\ 3 & 2.60-3.39 & \text { Rarely Implemented } \\ 2 & 1.80-2.59 & \text { Poorly Implemented } \\ 1 & 1.00-1.79 & \text { Not Implemented }\end{array}$

The level of eClaims quality service through Electronic Claims Submission (ECS). The results indicates that eClaims quality service through Electronic Claims Submission (ECS) is "Moderately Implemented" in terms of: It can submit claim online immediately (mean $=4.04, \mathrm{SD}=0.71$ ); It is a very high electronic solution in enhancing client satisfaction (mean $=3.74, \mathrm{SD}=0.76$ ); It improves consistency and data quality (mean $=3.81, \mathrm{SD}=0.62$ ); It improves the internal workflows in relation to PhilHealth transactions (mean $=3.85, \mathrm{SD}=0.86$ ); and It simplifies the record keeping (mean $=3.07 ; \mathrm{SD}=0.92)$. Overall, the authorized personnel "Moderately Implemented" eClaims quality service in terms of Electronic Claims Submission $(\mathrm{ECS})$ mean $=3.90, \mathrm{SD}=0.60)$.

As cited by Nsiah-Boateng et. al., (2017) the electronic-based claims review significantly adjusted higher amounts from healthcare provider claims than the paper-based review, indicating that it has a higher ability to detect spurious claims. Scaling up the electronic-based review to cover claims from all accredited healthcare providers could reduce cost to the scheme and ensure long term financial viability.

As the protection of information systems against unauthorized access to or modification of information whether in storage, processing or transit, and against the denial of service to authorized users or the provisions of service unauthorized users, including those measures necessary to detect, document, counter such threats. 
Table 3. Level of Claim Status Verification (CSV)

\begin{tabular}{|l|l|l|l|}
\hline Questions & Mean & SD & Remarks \\
\hline $\begin{array}{l}\text { It can easily track and verify the claim status } \\
\text { of the patient/member. }\end{array}$ & 4.41 & 0.75 & Fully Implemented \\
\hline $\begin{array}{l}\text { It can immediately verify the payment status } \\
\text { of a claim. }\end{array}$ & 4.22 & 0.97 & Fully Implemented \\
\hline $\begin{array}{l}\text { The verification of the claim status, responds } \\
\text { in a timely way. }\end{array}$ & 4.22 & 0.75 & Fully Implemented \\
\hline $\begin{array}{l}\text { It can effectively increase efficiency in terms } \\
\text { of claim status verification. }\end{array}$ & 4.04 & 0.65 & Moderately Implemented \\
\hline $\begin{array}{l}\text { It can quickly resubmit the corrected claims } \\
\text { electronically. }\end{array}$ & 4.30 & 0.99 & Fully Implemented \\
\hline Weighted Mean & $\mathbf{4 . 2 4}$ & $\mathbf{0 . 7 1}$ & Fully Implemented \\
\hline
\end{tabular}

Legend:

$\begin{array}{lll}\text { Scale } & \text { Range Remarks } \\ 5 & 4.20-5.00 & \text { Fully Implemented } \\ 4 & 3.40-4.19 & \text { Moderately Implemented } \\ 3 & 2.60-3.39 & \text { Rarely Implemented } \\ 2 & 1.80-2.59 & \text { Poorly Implemented } \\ 1 & 1.00-1.79 & \text { Not Implemented }\end{array}$

The level of eClaims quality service through Claim Status Verification (CSV). It illustrates the eClaims quality service through Claim Status Verification (CSV) which is "Moderately implemented" as it effectively increase efficiency in terms of verification process. It is "Fully Implemented" in terms of: It can easily track and verify the claim status of the patient/member (mean $=4.41, \mathrm{SD}=0.75$ ); It can immediately verify the payment status of a claim (mean $=4.22, \mathrm{SD}=0.97)$; The claim status verification, responds in a timely way $($ mean $=4.22, \mathrm{SD}=0.75)$; and It can quickly resubmit the corrected claims electronically $($ mean $=$ 4.30, $\mathrm{SD}=0.99$ ).

Generally, the eClaims quality service in terms of Claim Status Verification (CSV) is "Fully Implemented" $($ mean $=4.24, \mathrm{SD}=0.71)$.

Azmi et. al., (2016) cited that verification is a crucial stage in every verification system. The advancement of a modern system promoted the application of neural networks into identity verification systems. It is also where the developed software had its own authenticity in which the identity of a subject or resource can be proved to be the one claimed. 
Table 4. Composite Level of Implementation of eClaims in Government Hospitals in Laguna

\begin{tabular}{|c|c|c|c|}
\hline Indicators & $\begin{array}{l}\text { Weighted } \\
\text { Mean }\end{array}$ & Rank & Verbal Interpretation \\
\hline Claim Eligibility Web Service (CEWS) & 4.12 & 2 & Moderately Implemented \\
\hline Electronic Claims Submission (ECS) & 3.90 & 3 & Moderately Implemented \\
\hline Claim Status Verification (CSV) & 4.24 & 1 & Fully Implemented \\
\hline
\end{tabular}

Legend:

$\begin{array}{lll}\text { Scale } & \text { Range Remarks } \\ 5 & 4.20-5.00 & \text { Fully Implemented } \\ 4 & 3.40-4.19 & \text { Moderately Implemented } \\ 3 & 2.60-3.39 & \text { Rarely Implemented } \\ 2 & 1.80-2.59 & \text { Poorly Implemented } \\ 1 & 1.00-1.79 & \text { Not Implemented }\end{array}$

The composite level of implementation of eClaims. It revealed that the selected hospitals in District 4 "Moderately Implemented" the Claim Eligibility Web Service (WM=4.12, R=2) and the Electronic Claim Submission ( $\mathrm{WM}=3.90, \mathrm{R}=3$ ). While they "Fully Implemented" the Claim Status Verification (WM=4.24, $\mathrm{R}=1)$.

Generally, the eClaims system in the selected hospitals of District 4 is "Moderately Implemented".

Table 5. Perception of Authorized Personnel in the eClaims System's Benefits

\begin{tabular}{|l|c|l|}
\hline Questions & $\begin{array}{l}\text { Frequency of } \\
\text { Answer "Yes" }\end{array}$ & $\begin{array}{l}\text { Percen } \\
\text { tage }\end{array}$ \\
\hline $\begin{array}{l}\text { Can eClaims verify the eligibility of the patient/member to avail PhilHealth } \\
\text { benefits efficiently without any conflict? }\end{array}$ & 27 & 100.00 \\
\hline Is eClaims can be considered as a timely-manner system? & 27 & 100.00 \\
\hline Is there an optional way when there is a poor internet connection? & 17 & 62.96 \\
\hline Can you consider the eClaims as solution for the efficiency issues? & 22 & 81.48 \\
\hline Can the eClaims resubmit rejected claims quickly than before? & 23 & 85.19 \\
\hline Does the eClaims system improve the denial management system? & 11 & 40.74 \\
\hline $\begin{array}{l}\text { Does the submission of electronic claims allow anytime in real-time whether } \\
\text { in single form or in batch? }\end{array}$ & 25 & 92.59 \\
\hline $\begin{array}{l}\text { Does eClaims ensures security and confidentiality over personal information } \\
\text { processing and transmission? }\end{array}$ & 27 & 100.00 \\
\hline Does security breach in eClaims can be dealt with? & 18 & 66.67 \\
\hline Does eClaims improve the reimbursement process of claims? & 27 & 100.00 \\
\hline
\end{tabular}

The Level of Perception of Authorized Personnel in the eClaims System's Benefits. The result shows that the respondent's Level of Perception in the eClaims System, both the first question "Can eClaims verify the eligibility of the patient/member to avail PhilHealth benefits efficiently without any conflict?", the second question "Is eClaims can be considered as a timely-manner system?", the eight question "Does eClaims ensures security and confidentiality over personal information processing and transmission?", and the tenth question "Does eClaims improve the reimbursement process of claims?" got the highest frequency of 27 with 
a percentage of 100.00 . While the sixth question got the lowest frequency of 11 with a percentage of 40.74 where 11 out of 27 authorized personnel understand that eClaims system do not improve the denial management of all the submitted claims.

Table 6. Significant Effect of eClaims Quality Service to the Implementation of Philhealth Circular No. 30, S2017

\begin{tabular}{|l|c|c|c|c|c|c|}
\hline & \multicolumn{6}{|c|}{ P values } \\
\hline & Q3 & Q4 & Q5 & Q6 & Q7 & Q9 \\
\hline CEWS & 0.036 & 0.144 & 0.996 & 0.049 & 1.000 & 0.058 \\
\hline ECS & 0.297 & 0.626 & 0.998 & 0.567 & 0.997 & 0.219 \\
\hline CSV & 0.312 & 0.525 & 1.000 & 0.635 & 0.997 & 0.05 \\
\hline
\end{tabular}

The effect of eClaims quality service to the implementation of Philhealth Circular No. 30, S-2017. The results show that Claims Eligibility Web Service (CEWS), has a significant effect to the implementation of Philhealth Circular No. 30, S-2017 ( $\mathrm{p}$ - values < 0.05). While the rest of the indicators of eClaims quality service are not significant ( $\mathrm{p}$ - values) which suggest they do not have a significant effect to the implementation of Philhealth Circular No. 30, S-2017.

\section{Conclusions}

Based on the findings of the study the following conclusions were drawn:

1. Based on the demographic profile of the authorized personnel of Government Hospitals, there is greater number of 26-35 years old and female is the most predominant gender of the respondents. While in terms of years in service, the greater number of respondents works within less than six (6) years and most of them are Billing Clerks in terms of designation.

2. Based on the data gathered, both Claim Eligibility Web Service (CEWS) and Electronic Claim Submission (ECS) are on its halfway in executing the Philippine Health Insurance Corporation (PhilHealth) mandate regarding to the full implementation of eClaims System. On the other side, Claim Status Verification (CSV) carry out the fulfillment of the PhilHealth Circular No. 30, s-2017.

3. It can be concluded that the Electronic Claims (eClaims) System are partially implemented in the selected hospitals in District 4.

4. As to the level of perception of authorized personnel in the eClaims system, some of them are not yet convince that the eClaims system really improves the denial management system of all the submitted claims.

5. Therefore, the researcher's hypothesis that there is no significant effect between the PhilHealth Circular No. 30, s-2017 on the level of implementation of selected hospitals in District 4 is rejected. There is significant effect as it takes time to completely execute the eClaims system in order to use the whole features efficiently and effectively. 


\section{Recommendations}

In view of the conclusions, the following recommendations were given as follows:

1. Given that this study provides an average result or difference in Claim Eligibility Web Service (CEWS) and Electronic Claim Submission (ECS) which is more likely increase the effectivity and efficiency of the eClaims System, the researcher highly recommends to the respective agency to update and to enhance this two phases of eClaim System which could fully complete the essential features and implementation of the said system.

2. To the Philippine Health Insurance Corporation (PhilHealth), they may actively monitor the compliance of all of their Accredited Health Care Institution (HCI) which could reduce the length of their compliance.

3. The researcher recommends to conduct seminars or trainings to all the authorized personnel in order to disseminate additional information about the eClaims particularly about its importance and advantage.

4. Must continue to develop and sustain an update and program for the improvement of the employee's performance in order to enhance clients' satisfaction.

5. This study can be used as another reference for the future researchers who will conduct the same study.

\section{References}

Ahrendt et. al., (2017). “Verifying data- and control-oriented properties combining static and runtime verification: theory and tools.” Form Methods Syst Des, 51:200-265 doi: 10.1007/s10703-0170274-y

Alsoub et. al., (2017). “User Acceptance Criteria for Enterprise Resource

American Medical Association (AMA) \& Connecticut State Medical Association (2013). "The Benefits of electronic claims submission - improve practice efficiencies. "Planning Software Systems." 14(1): 297-307 ISSN: 1349-4198

Azmi et. al., (2016). "Biometric signature verification system based on freeman chain code and $k$-nearest neighbor.” Multimed Tools Appl (2017), 76:15341-15355 doi: 10.1007/s11042-016-3831-2

Cagaoan et. al., (2014). “Privacy Awareness in E-commerce.” International Journal of Education and Research, Vol. 2(1) Online ISSN: 2201-6740

Chang \& Mao-Sheng (2016). “A novel software-defined wireless network to improve ship area network performance."

Chavan (2013). “Internet Banking-Benefits and Challenges in an Emerging Economy.” International Journal of Research in Business Management, Vol. 1(1), 19-26

Collo et. al., (2017). “CS ONLINE: An Online Clerical Service System for the Guidance Office.” Unpublished Thesis, Laguna State Polytechnic University - Santa Cruz Campus. 
Cowie et. al., (2016). “Electronic health records to facilitate clinical research" Clin Res Cardiol, 106: 1-9 doi: 10.1007/s00392-016-1025-6

Cucciniello et. al., (2015). “Understanding key factors affecting electronic medical record implementation: a socio technical approach.” BMC Health Services Research 15:268 doi: 10.1186/s12913-0150928-7

Doods et. al., (2014). “A European inventory of common electronic health record data elements for clinical trial feasibility." Trials 15:18 doi: $10.1186 / 1745-6215-15-18$

Elkhenini et. al., (2015). “Using an Electronic Medical Record (EMR) to Conduct Clinical trials: Salford Lung Study Feasibility." BMC Medical Informatics and Decision Making 15:8 doi: 10.1186/s12911-015-0132-z

Gong et. al., (2015). “Real-time GIS data model and sensor web service platform for environmental data management.” International Journal of Health Geographics, 14:2 doi: 10.1186/1476-072x-14-2

Guilong (2013). “Axiomatic systems for rough sets and fuzzy rough sets.” doi: 10.1016/j.ijar.2008.02.001

Hawley et. al., (2014). "Sharing of Clinical data in a Maternity Setting: How do paper hand-held records and electronic health records compare for completeness?” BMC Health Services Research, 14:650 doi: 10.1186/s12913-014-0650-X

Huynh et. al., (2016). “A bitwise-based indexing and heuristic-driven on-the-fly approach for Web service composition and verification.” Vietnam J Comput Sci, 4:111-126 doi: 10.1007/s40595-016-00798

Jain et. al., (2015). “Double Orbit finite retrial queues with priority customers and service interruptions." Applied Math Computations, 253: 324-344

Khan, A. (2016). “Electronic Commerce: A Study on Benefits and Challenges in an Emerging Economy." Global Journals Inc. (USA), Vol. 16(1). Online ISSN: 2249-4588.

Kiberu et. al., (2014). "Strengthening district-based health reporting through the district health management information software system: the Ugandan experience.” BMC Medical informatics and Decision Making, 14:40 doi: 10.1186/1472-6947-14-40

Lai, P. C. (2016). “Design and Security impact on consumers' intention to use single platform Epayment, Interdisciplinary Information Sciences.” 22 (1), 111-122

Liu et. al., (2016). “Reliability and Validity of an Indicator system for Assessing the Quality of Ophthalmic Nursing.” Chi. Nurs. Res. 3:158-161 doi: 10.1016/j.cnre.2016.11.004 
Mastellos et. al., (2016). "Feasibility of extracting data from electronic medical records for research: An International Comparative Study.” BMC Medical Informatics and Decision Making 16-90 doi: 10.1186/s12911-016-0332-1

Miguel et. al., (2014) “A Review of Service Quality Models for the Evaluation of Software Products.” 5(6): $31-53$

Nagamouttou et. al., (2015). “A verification strategy for web services composition using enhanced stacked automata model.” SpringerPlus, 4:98 doi: 10.1186/s40064-015-0805-1

Nanehkaran, Y. A. (2013). “An Introduction to Electronic Commerce.” International Journal of Scientific \& Technology Research, Vol. 2(4), pp.190-193.

Nsiah-Boateng et. al., (2017). "Reducing medical claims cost to Ghana's National Health Insurance scheme: a cross-sectional comparative assessment of the paper- and electronic-based claims reviews. ” BMC Health Services Research, 17:115 doi:10.1186/s12913-017-2054

Ohidujjaman et. al., (2015). “E-commerce Challenges, Solutions and Effectiveness Perspective Bangladesh.” International Journal of Computer Applications, Vol. 70(9). 9-17

Orrenius \& Zavodny (2016). “Do state work eligibility verification laws reduce unauthorized immigration?” IZA Journal of Migration, 5:5 doi: 10.1186/s40176-016-005

Rogers (2003). “Diffusion of Innovations.” 5th ed. New York: The Free Press

Salleh et. al., (2017). “An Overview of Software Functionality Service: A Systematic Literature Review.” Procedia Computer Science 124(2017) 337-344

Schauble et. al., (2017) “Consumers' Intention to Use a Single Platform E-Payment System: A Study among Malaysian Internet and Mobile Banking Users.” (20) (1) 1-13

Singer \& Fernandez (2015). “The effect of electronic medical record system use on communication between pharmacists and prescribers.” BMC Family Practice 16:155 doi: 10.1186/s12875-015-0378-7

Soti et. al., (2015). "Feasibility of an innovative electronic mobile systemto assist health workers to collect, complete, verify, and timely datain a Malaria Control.” Malaria Journal 14:430 doi: 10.1186/s12936-015-0965-z

UNCTAD (2015). "Information economy report 2005: Unlocking the Potentials of e-commerce for developing countries.” United Nations Publication

Vining et. al., (2014). “Eligibility determination for clinical trials: development of a case review process at a chiropractic research center.” Trials, 15:406 doi: 10.1186/1745-6215-15-406

Weng et. al., (2015). “Visual aggregate analysis of eligibility features of clinical trials.” Journal of Biomedical Informatics Vol.25: 241-255 
Yang et. al., (2016). “Mindbot: a social-based medical virtual assistant in 2006.” IEEE International Conference on Healthcare Informatics (ICHI), IEEE2016, pp. 318.

Zhang et. al., (2017). “A deep learning approach for predicting the quality of online health expert question-answeig services." Journal of Biomedical Informatics 71:241-253 doi: 10.1016/j.jbi.2017.06.012

Zobel et. al., (2017). “Automated detection of records in biological sequence databases that are inconsistent with the literature.” Journal of Biomedical Informatics 7, 229-240 doi: 10.1016/j.jbi.2017.06.015

Stadler et. al., (2016). “Design of a Secure Mobile Business Communication Platform Utilizing Next Generation Web Technologies.”

Browman et. al., (2013). “Impact of Electronic Health Record Systems on Information Integrity: Quality and Safety Implications. ” https://www.ncbi.nlm.nih.gov/pmc/articles/pmc3797550

Bridgestone (2017). “Claim Status Tracking \& Verification.”

http://www.bridgestonehrs.com/products/claim-status-verification/ Accessed Sept 10, 2018

Doherty et. al., (2013). “Factors affecting the Successful Realization of Benefits from Systems Development Projects: Findings from three case studies.” Journal of Information Technology. Retrieved from http://www.som.cranfield.ac.uk/som/dinamic-content/media/ISRC/factors affecting the successful realization of benefits from systems development

Emblem Health (2018). “Electronic Claims Submission.” https://www.emblemhealth.com/providers/providermanual/claims/electronic-claims-submission Accessed Sept 10, 2018zFenza (2013). “Mindswap Maryland Information and Network Dynamics Lab Semantic Web Agents Project." http://www.mindswap.org

Garfield, S. (2017). “Archiving, Document Management, and Records Management." https://sites.google.com/site/stangarfield/

Management Hub (2014). “Managing Information System.” https://www.managementhub.com

PhilHealth Circular No. 21 s. 2014. “Guidelines for eClaims System Simulation” www.philhealth.gov.ph

PhilHealth Circular No. 16 s. 2016. “Full Implementation of the Electronic Claims System” www.philhealth.gov.ph

PhilHealth Circular No. 30 s. 2017. “Implementation of the Electronic Claims Systems Using Hybrid Approach” www.philhealth.gov.ph

PhilHealth eClaims Implementation Guide (2013) www.philhealth.gov.ph

Shinder D. (2013). “Planning File Server Security” http://www.windowsecurity.com/blogs/shinder/microsoft securityspace/01 planning-fileserver-security-54.html 
